\title{
O SERVIÇO PÚBLICO DE COMUNICAÇÃO SOCIAL COMO RECURSO DA POLÍTICA CULTURAL A experiência portuguesa, 2002-2012
}

\author{
Augusto Santos Silva \\ Universidade do Porto, Portugal \\ Maria José Ribeiro \\ Câmara Municipal de Lisboa, Portugal
}

\begin{abstract}
Resumo: Não é frequente, em Portugal, a consideração do serviço público de rádio e televisão como um recurso disponível para a política cultural. E, quando ocorre, ela fica demasiado presa de argumentações casuísticas e impressionistas. Contudo, dispomos de uma cópia assinalável de elementos que permitiriam sustentar em bases mais analíticas o debate, académico ou político, desta questão. Abordando a experiência portuguesa entre 2002 e 2012, este artigo examina a relevância do serviço público de comunicação social como recurso cultural. É uma área importante para a investigação empírica conduzida pelos critérios das ciências da comunicação, da sociologia ou da economia. E implica fazer uma leitura objetiva e distanciada dos quadros normativos e das concretas condições de cumprimento, das estratégias de ação e dos respetivos indicadores de desempenho e resultado.
\end{abstract}

Palavras-chave: cultura; política cultural; serviço público de media.

\section{A relevância cultural do serviço público}

Não é frequente, em Portugal, a consideração do serviço público de rádio e televisão como um recurso disponível para a política cultural. E, quando ocorre, ela fica demasiado presa de argumentações casuísticas e impressionistas. Contudo, dispomos de uma cópia assinalável de elementos que permitiriam sustentar em bases mais analíticas o debate, académico ou político, desta questão: desde os textos que estabelecem o enquadramento doutrinário, legal e contratual do serviço público aos indicadores de desempenho e resultados e às auditorias e avaliações promovidas pelos órgãos competentes de acompanhamento e de regulação.

A questão faz todo o sentido.

Por um lado, a televisão e a rádio são os mais poderosos meios de comunicação de massas. Chegam a quase todas as famílias e, salvo os canais de acesso condicionado, de forma gratuita. Os seus consumos encontram-se entre as práticas culturais mais difundidas. No inquérito promovido pelo Plano Nacional de Leitura e administrado, em 2006-2007, a uma amostra de 2.552 indivíduos, 98\% dos inquiridos declararam ver diariamente ou quase a televisão, 86\% declararam ver televisão mais do que uma hora por dia e 71\% declararam ouvir diariamente ou quase rádio (cf. Neves, 2011: 266, 278). 
No inquérito promovido pela Entidade Reguladora da Comunicação Social, e administrado em 2007 a uma amostra de 2.205 indivíduos, a "utilização" destes dois meios compara com o recurso regular a jornais, revistas livros, cinema e computador do modo que indica o Quadro 1:

Quadro 1: Utilização de media por grupo etário, 2007 (em \%)

\begin{tabular}{|c|c|c|c|c|}
\hline Meio & $15-30$ anos & $31-50$ anos & $51-64$ anos & $65+$ anos \\
\hline Televisão & 99,1 & 99,3 & 99,9 & 99,8 \\
\hline Rádio & 79,9 & 78,7 & 65,9 & 55,2 \\
\hline Jornais & 61,4 & 68,4 & 59,9 & 32,9 \\
\hline Revistas & 52,5 & 49,3 & 40,6 & 17,6 \\
\hline Livros & 58,9 & 41,8 & 35,1 & 16,4 \\
\hline Cinema & 71,8 & 41,0 & 26,1 & 6,0 \\
\hline Computador & 70,4 & 42,2 & 21,0 & 2,4 \\
\hline
\end{tabular}

Fontes: Rebelo, 2008: 68.

Mesmo o processo em curso de repolarização da cultura do ecrã em torno do computador e da internet não põe em crise o papel da televisão, embora o reconfigure. Nas palavras de Gustavo Cardoso (2006: 229-230, 259), a televisão é o "elemento central do meta-sistema do entretenimento" - sistema que inclui também o cinema, a música ou os jogos multimédia - e partilha agora com a internet o "papel central” do "meta-sistema da informação" (cf. também Cardoso, Espanha \& Araújo, 2009). A política cultural não pode, pois, dispensar-se de olhar para este meio, da mesma forma que olha para as artes e as demais indústrias culturais.

Por outro lado, a relevância cultural e formativa do serviço público de rádio e televisão constitui, para a teoria e a política que o defendem, e sobretudo na variante europeia, o próprio fundamento da sua existência, juntamente com a isenção e o pluralismo na informação. A cultura está contemplada na tríade que lhe serviu de inspiração, desde a fundação da BBC: "informar, formar, divertir”; e é também uma das marcas que, de acordo com outra fórmula habitual, justificaria a ambição de ser, a televisão pública, uma "televisão popular de qualidade".

A investigação tem mostrado os equívocos a que conduziu a expectativa de que a televisão pública, generalista e de acesso universal e gratuito se pudesse tornar numa grande "escola popular" - e as subsequentes deceções de muitos setores das elites europeias (cf. Pinto, 2002: 22). Coisa análoga sucede na relação entre televisão e ação cultural: são também suficientemente conhecidas as descontinuidades entre uma e outra. "Para certas formas de cultura, escreveu Dominique Wolton (1999: 123), a televisão não é o melhor instrumento de comunicação".

Mas a necessária relativização da inserção da televisão no sistema de recursos culturais não deve fazer apagar essa mesma inserção e o correlativo potencial, em termos de 
política cultural. Nem o fim do monopólio público da televisão e a abertura do setor à concorrência, nem a atual passagem à era digital provocaram tal apagamento. Em novas condições - forte concorrência entre conteúdos e entre plataformas de distribuição, expansão dos serviços e conteúdos de acesso pago, erosão das audiências da televisão generalista de acesso livre, novos fatores de questionamento do serviço público e novos desafios à sua organização e atividade - a dimensão cultural da televisão e, especificamente, a relevância cultural da televisão pública, em todos os seus serviços e não apenas no canal mais orientado para as minorias, continuam a constituir, ao mesmo tempo, um facto social e uma matéria de opções e medidas políticas.

É, aliás, o alcance da televisão em termos de cidadania e de cultura que serve de fundamento aos enquadramentos normativos particulares que a legislação europeia lhe reserva, quer quanto à autorização ou licenciamento de serviços, quer quanto às obrigações legais a que eles podem ser sujeitos, quer quanto à existência e à missão dos serviços públicos. Quer a diretiva comunitária “Televisão sem Fronteiras”, de 1989 e alterada em 1997, quer aquela que, em 2007, a substituiu - a Diretiva "Serviços de Comunicação Audiovisual" - consagram derrogações ao regime geral de concorrência e preveem certas obrigações (em termos, por exemplo, de língua utilizada e de quotas para produção europeia, produção originariamente em língua nacional e produção independente), em nome da necessidade de acautelar a diversidade das expressões culturais e de promover a identidade cultural (de cada Estado-membro e da Europa como tal). Logicamente, tais obrigações impendem sobretudo sobre as televisões generalistas de acesso livre; e são reforçadas no caso do serviço público.

Pode dizer-se, em síntese, que a rádio (a que se aplicam, mutatis mudandis, várias destas considerações doutrinárias e disposições normativas) e a televisão são abordáveis quer do ponto de vista dos direitos de cidadania (designadamente, a liberdade de expressão, os direitos de informação e os direitos culturais), quer do ponto de vista da coesão social, quer do ponto de vista (interligado ao anterior, de resto) da identidade cultural, quer do ponto de vista da diversidade das expressões culturais. Observado a partir de qualquer deles, o serviço público tem finalidades, obrigações e potencialidades específicas e, por comparação com os canais comerciais, adicionais. Falar do serviço público de rádio e televisão como um recurso da política cultural significa, pois, tentar apreender tais potencialidades.

\section{A experiência portuguesa entre 2002 e 2012}

Ora, como fazê-lo num registo analítico, capaz de contribuir para o debate doutrinário e político com elementos próprios de informação e interpretação? 
É aqui que, a nosso ver, a experiência portuguesa pode ser considerada com proveito. Na década que vai de 2002 a 2012, e é facilmente tratável como um período homogéneo e distinto dos anteriores, assim como, provavelmente, do que se prenuncia como futuro próximo, o serviço público de comunicação sofreu uma importante intervenção de política pública, que alterou significativamente vários dos seus pilares estruturais sobretudo no que toca ao modo de financiamento, à estrutura organizativa e, na televisão, ao desempenho em termos de conteúdos e audiências.

No início de 2002, e nas palavras de Alberto Arons de Carvalho (2009: 388), a RTP, então concessionária do serviço público de televisão, "atravessava porventura a mais grave crise desde a sua fundação". Constituía um dos motivos mais acesos da disputa entre os partidos de governo, o que contrastava flagrantemente com a tradição europeia de consenso interpartidário em torno do serviço público. Foi um dos temas mais presentes no processo eleitoral de 2002, que haveria de conduzir à substituição do governo minoritário do PS pela coligação entre PSD e CDS-PP. O PSD fez inscrever no seu programa eleitoral a possibilidade de amputação do serviço público das suas componentes mais diretamente culturais: a Antena 2, dedicada à música erudita, na RDP e o segundo canal generalista da RTP. O Governo Durão Barroso haveria de moderar bastante estes propósitos, mantendo a Antena 2 e optando por uma figura híbrida para a RTP 2, formalmente retirada do contrato de concessão geral do serviço público de televisão e, ao abrigo de uma concessão especial, permanecendo por um prazo de oito anos na gestão pública até que viesse a ser entregue a uma denominada entidade representativa da sociedade civil. O magazine "Acontece", emblemático do tipo de informação cultural então privilegiado no segundo canal televisivo, foi ostensivamente eliminado.

O ciclo começou, pois, com um pico de debate político desfavorável ao serviço público de comunicação social e à sua vertente mais próxima de uma dimensão cultural. A evolução das coisas seguiria, por razões que não há agora espaço para detalhar, um rumo substancialmente diferente. Por um lado, foi encontrada aquela solução de compromisso para a RTP 2; por outro lado, nomeada uma nova administração, encetou-se um processo de reestruturação financeira da empresa assente num claríssimo aumento do financiamento público, na redução do endividamento e numa redução também significativa dos custos operacionais. Esse processo foi prosseguido e desenvolvido, em 2005-2011, pelos dois governos socialistas $^{1}$; e contribuiu

\footnotetext{
1 - Os autores tiveram responsabilidades na política para a comunicação social do primeiro desses governos (o XVII, entre 2005 e 2009): Augusto Santos Silva, como ministro dos Assuntos Parlamentares, com a tutela da política para os media, e Maria José Ribeiro como sua chefe de gabinete.
} 
sobremaneira para a superação da crise estrutural da empresa, para a recuperação da sua legitimidade social e para a formação de um inédito, embora precário, consenso interpartidário em torno do serviço público.

Ora, definido pelo novo governo de coligação PSD/CDS-PP (retomando, aliás, o programa de 2002) o objetivo de privatizar, em 2012, um dos dois canais generalistas da televisão pública - o que rompe o consenso entre os dois maiores partidos portugueses e o ajustamento ao modelo europeu - anuncia-se a abertura de um novo ciclo. Razão bastante, na nossa perspetiva, para isolar o período 2002-2012 como um só caso, e distinto, de observação ${ }^{2}$. Uma observação tanto mais útil quanto puder identificar informação relevante para o desenho e a avaliação do novo ciclo.

\section{Mudanças profundas no serviço público de televisão}

O serviço público de rádio conheceu relativamente poucas mudanças no período que analisamos. É certo que deixou de ser prestado por uma empresa autónoma (a RDP), a qual se fundiu com a RTP para dar origem a uma concessionária única dos dois serviços (mantendo-se a marca RTP). A taxa que o financiava em exclusivo foi transformada numa contribuição para o audiovisual, cuja receita passou a reverter também para a televisão. Mas o contrato de concessão, datado já de 1999, permaneceu inalterado. À sua luz, e também em função das obrigações legais específicas, os elementos distintivos da rádio pública, face às rádios privadas, e no que tange às questões de programação, são três: um canal próprio dedicado à música erudita (em sentido lato); uma quota de música portuguesa (na definição legal) de 60\%, na Antena 1, bastante superior à estabelecida para as rádios privadas (e que pode variar entre os $25 \%$ e os $40 \%$ ); e uma diferenciação do canal orientado para a audiência juvenil, a Antena 3, face aos restantes canais do seu segmento, em virtude do maior peso que concede ao campo musical português de pop/rock. A estes elementos de programação articulam-se práticas análogas de patrocinato, promoção, parceria e cobertura noticiosa. Pode dizer-se, pois, que a rádio pública intervém no plano cultural em função de duas orientações fundamentais - a promoção da língua e cultura nacional, a defesa da diversidade das

\footnotetext{
2 - Esse objetivo não viria a ser cumprido. Divergências públicas entre os dois partidos da coligação adiaram sucessivamente, ao longo de 2012, a decisão sofre o futuro da RTP, hesitando o Governo sobre cenários tão diversos como a privatização total de um canal, a privatização parcial da empresa (todavia, com gestão entregue ao parceiro minoritário!...) ou a concessão do serviço público a privados. Posteriormente à redação e apresentação deste artigo (que datam de abril de 2012), o Governo viria a decidir, em janeiro de 2013, o adiamento sine die da privatização da RTP e o início de um novo processo de reestruturação, cujos elementos principais serão a eliminação da indemnização compensatória proveniente do Orçamento de Estado (cingindo-se as receitas, de em $2014 \mathrm{em}$ diante, à soma da contribuição audiovisual e da publicidade) e a redução muito significativa do quadro de pessoal da empresa. (Esta nota foi acrescentada em janeiro de 2013).
} 
expressões através da divulgação de expressões minoritárias. Em particular, a funcionalidade da antena clássica no quadro do sistema artístico português envolvido, digamos, na música cultivada, não é publicamente disputada - embora estalem periodicamente vivas polémicas sobre as opções em concreto de programação. O valor e a singularidade do arquivo sonoro da rádio pública tem feito dele parte integrante do projeto (ainda por concluir) de constituição de uma fonoteca nacional.

São mais profundas e significativas as mudanças ocorridas na televisão - e sobre elas concentraremos doravante a nossa atenção.

É clara a alteração do enquadramento legal, contratual e regulatório do serviço público - e julgamos não constituir matéria de controvérsia analítica a identificação dos seus efeitos na dimensão propriamente cultural daquele serviço.

Assim, quanto às obrigações, em 2007, a nova Lei da Televisão (Lei n. ${ }^{0}$ 27/2007, de 30 de julho), que densificou as obrigações de todos os operadores licenciados e tornou mais exigente a avaliação do seu cumprimento, reforçou especificamente as obrigações do serviço público. A revisão da Lei, em 2011 (Lei n. ${ }^{\circ}$ 8/2011, de 11 de abril), transpondo para a ordem jurídica nacional a Diretiva "Serviços de Comunicação Audiovisual”, manteve estas duas orientações fundamentais. Por efeito da citada lei de 2007, o segundo canal generalista regressou plenamente à concessão geral do serviço público, pondo-se fim à situação ambígua em que havia sido colocado em 2003. Retomando e desenvolvendo a inovação do contrato de concessão de 1997, o contrato de concessão do serviço público de televisão em vigor para o quadriénio 2008-2011 fixou metas quantitativas para o cumprimento das obrigações, em todos os canais abrangidos. As Tabelas 1 e 2, que procuram sistematizar as metas relativas aos programas de cultura, conhecimento e educação, evidenciam este salto qualitativo: o desenho concreto de requisitos mínimos verificáveis, não interferindo em si mesmo nas escolhas de programação e deixando uma ampla margem de exercício da independência dos respetivos responsáveis, estabelecia, ainda assim, um caderno de encargos e impunha mais enfaticamente a atenção às finalidades culturais associadas ao serviço público. 
Tabela 1: As obrigações do primeiro canal de serviço público de televisão em matéria de cultura, conhecimento e educação, estabelecidas no contrato de concessão de 2008

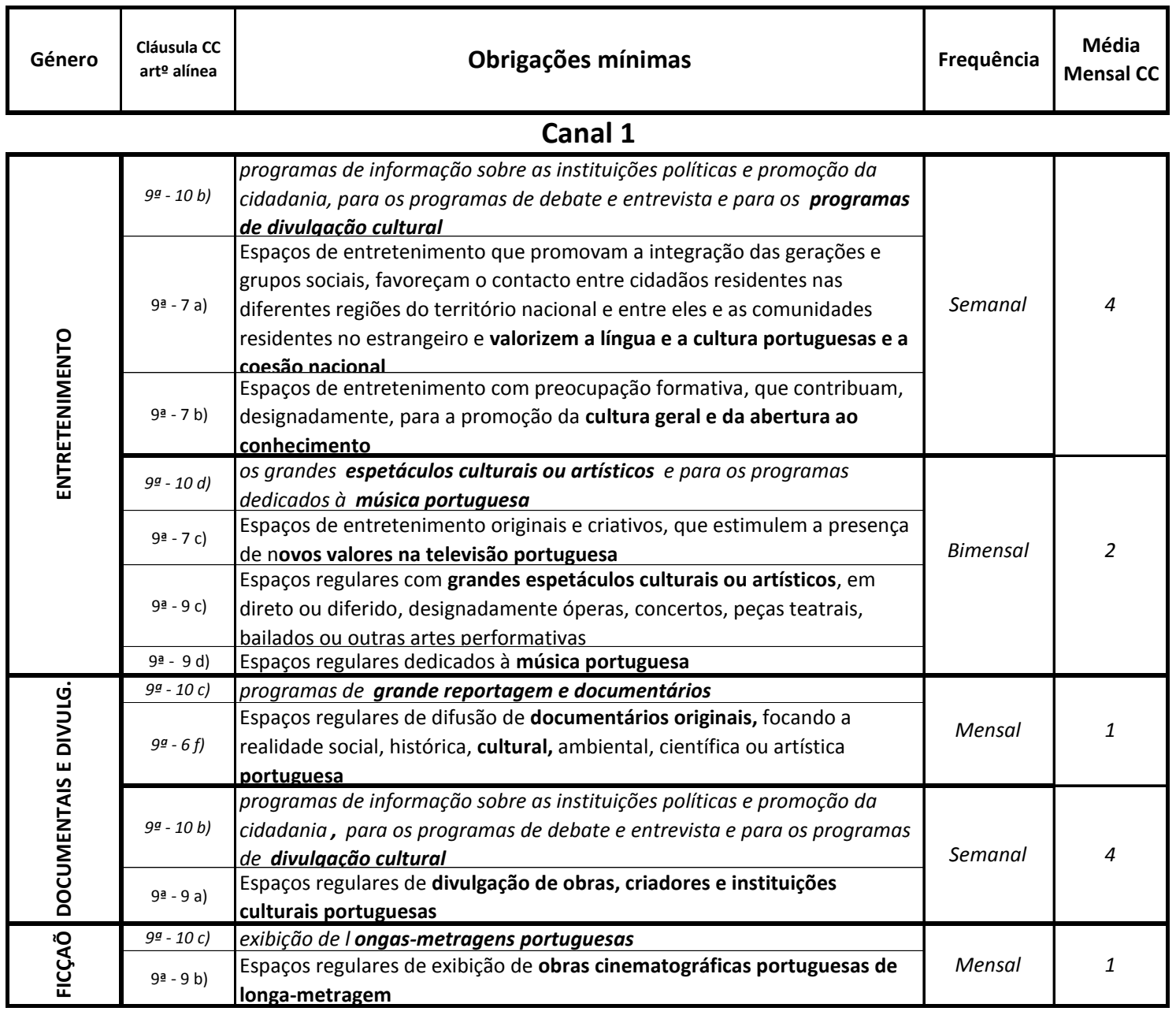

Fonte: Contrato de Concessão do Serviço Público de Televisão, 2008 
Tabela 2: As obrigações do segundo canal de serviço público de televisão em matéria de cultura, conhecimento e educação, estabelecidas no contrato de concessão de 2008

\begin{tabular}{|c|c|c|c|c|}
\hline Género & $\begin{array}{l}\text { Cláusula CC } \\
\text { arto alínea }\end{array}$ & Obrigações mínimas & Frequência & $\begin{array}{l}\text { Média } \\
\text { Mensal CC }\end{array}$ \\
\hline & \multicolumn{4}{|c|}{ Canal 2} \\
\hline \multirow{10}{*}{ 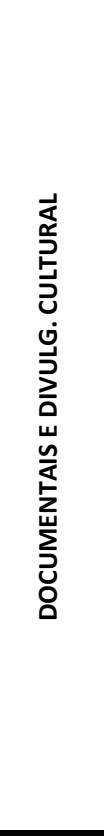 } & $\left.10^{a}-14 d\right)$ & generalidade dos restantes programas & \multirow{10}{*}{ Semanal } & \multirow{10}{*}{4} \\
\hline & $10^{a}-11$ d) & $\begin{array}{l}\text { Espaços regulares de informação e debate culturais, com especial atenção } \\
\text { à atualidade artística nacional }\end{array}$ & & \\
\hline & $10 \mathrm{a}-11 \mathrm{e})$ & $\begin{array}{l}\text { Espaços regulares de entrevistas com personalidades da vida cultural } \\
\text { portuguesa cobrindo a literatura, as artes, o património, o pensamento, a } \\
\text { ciência e outras áreas }\end{array}$ & & \\
\hline & $10 \mathrm{a}-11 \mathrm{f})$ & $\begin{array}{l}\text { Espaços regulares de debate sobre temas sociais, que tenha em conta a } \\
\text { pluralidade e a representatividade das organizações não governamentais }\end{array}$ & & \\
\hline & $10 \mathrm{a}-12 \mathrm{~b})$ & $\begin{array}{l}\text { Espaços regulares de programação dedicados à divulgação e debate de } \\
\text { temas que promovam o exercício da cidadania, tais como participação } \\
\text { política, ambiente, defesa do consumidor, ação e solidariedade social ou } \\
\text { igualdade de género }\end{array}$ & & \\
\hline & $10 \mathrm{a}-12 \mathrm{c})$ & Espaços regulares dedicados ao ensino à distância & & \\
\hline & $\left.10^{a}-13 b\right)$ & Espaços regulares de divulgação do livro e da leitura & & \\
\hline & $10 \mathrm{a}-13 \mathrm{~h})$ & $\begin{array}{l}\text { Espaços regulares de sensibilização dos telespectadores para as técnicas e } \\
\text { linguagem próprias dos meios de comunicação social, promovendo o seu } \\
\text { sentido crítico }\end{array}$ & & \\
\hline & $10 \mathrm{a}-13 \mathrm{j})$ & $\begin{array}{l}\text { Espaços regulares especificamente direcionados para as pessoas com } \\
\text { necessidades especiais }\end{array}$ & & \\
\hline & $10 \mathrm{a}-13 \mathrm{I})$ & $\begin{array}{l}\text { Espaços regulares especificamente direcionados para as comunidades } \\
\text { imigrantes e minorias étnicas presentes em Portugal }\end{array}$ & & \\
\hline \multirow{6}{*}{ 迩 } & $10^{\underline{a}-14 c)}$ & $\begin{array}{l}\text { obras cinematográficas de longa-metragem do moderno cinema } \\
\text { português }\end{array}$ & & \\
\hline & $10 \mathrm{a}-13 \mathrm{c})$ & $\begin{array}{l}\text { Espaços regulares de divulgação de obras cinematográficas de longa- } \\
\text { metragem do moderno cinema português, o que inclui produções dos vinte } \\
\text { anos anteriores à transmissão }\end{array}$ & Mensal & 1 \\
\hline & $10^{\underline{a}-14 d)}$ & generalidade dos restantes programas & \multirow{4}{*}{ Semanal } & \multirow{4}{*}{4} \\
\hline & $10 \mathrm{a}-13 \mathrm{~d})$ & $\begin{array}{l}\text { Espaços regulares dedicados à cinefilia, com uma forte componente } \\
\text { pedagógica, que contextualizem as obras difundidas na história do cinema }\end{array}$ & & \\
\hline & $10 \mathrm{a}-13 \mathrm{e})$ & $\begin{array}{l}\text { Espaços regulares dedicados ao cinema europeu e a cinematografias } \\
\text { menos representadas no circuito comercial de exibição }\end{array}$ & & \\
\hline & $\left.10^{a}-13 f\right)$ & Espaços regulares dedicados a curtas-metragens e ao cinema de animação & & \\
\hline \multirow{4}{*}{ 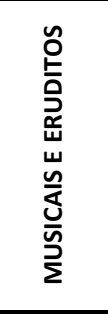 } & $10^{\underline{a}-14 b)}$ & $\begin{array}{l}\text { espaços de debate sobre temas sociais e para espetáculos } \\
\text { representativos de culturas ou artes de menor visibilidade }\end{array}$ & \multirow[b]{2}{*}{ Quinzenal } & \multirow[b]{2}{*}{2} \\
\hline & $\left.10^{a}-13 a\right)$ & $\begin{array}{l}\text { Espaços regulares, em direto ou diferido, com espetáculos representativos } \\
\text { de culturas ou artes de menor visibilidade, designadamente e de forma } \\
\text { equilibrada, concertos de música erudita, etnográfica e jazz, peças teatrais } \\
\text { ou bailados }\end{array}$ & & \\
\hline & $10^{\underline{a}-14 d)}$ & generalidade dos restantes programas & \multirow[b]{2}{*}{ Semanal } & \multirow[b]{2}{*}{4} \\
\hline & $10^{\underline{g}-13 \mathrm{~g})}$ & $\begin{array}{l}\text { Espaços regulares de promoção e divulgação da produção musical } \\
\text { portuguesa }\end{array}$ & & \\
\hline
\end{tabular}

Fonte: Contrato de Concessão do Serviço Público de Televisão, 2008

Por outro lado, tendo em vista as novas condições de desenvolvimento do serviço público no quadro da era digital, quer a Lei da Televisão de 2007 quer o contrato de concessão de 2008 indicaram como uma das vias principais para a afirmação do sentido do serviço público, da sua relevância social e da diferenciação face aos demais 
atores do panorama televisivo concorrencial, a aposta nas áreas do conhecimento e da formação. Assim, a empresa ficou explicitamente autorizada a avançar com novos serviços de programas, desde que fossem dirigidos à divulgação do conhecimento e à juventude.

Finalmente, as mudanças introduzidas entre 2006 e 2008 reforçaram substancialmente o quadro de regulação, escrutínio e acompanhamento do serviço público. Falamos da criação da ERC, Entidade Reguladora da Comunicação Social, do reforço das competências do Conselho de Opinião da RTP, da criação do Provedor do Telespectador (assim como do Provedor do Ouvinte), da previsão expressa do acompanhamento parlamentar da atividade da empresa, seja ao nível da gestão, seja ao nível das direções de informação e programação ${ }^{3}$.

Portanto: novas obrigações, novas exigências de demonstração e de verificação do seu cumprimento, regulação reforçada - o que representa, no seu conjunto, a acentuação da identidade, da responsabilidade e da accountability do serviço público, seja do ponto de vista do "informar", seja do ponto de vista do "entreter" e do "formar".

É, evidentemente, mais difícil apreender e caraterizar a evolução ocorrida nos conteúdos de programação do serviço público. E, contudo, não é menos evidente que esse é o plano mais decisivo, para avaliar as suas potencialidades como recurso da política cultural.

Embora predomine a opinião impressionista, aliás usualmente emitida de forma muito assertiva e com vasta cópia de argumentos de autoridade, tem havido, entre nós, algum esforço para tratar a questão no plano analítico - e recorrendo à investigação empírica. Focando mais a dimensão da informação do que a da programação, mesmo assim com indicações interessantes para um ponto que nos é capital, qual seja a in/diferenciação do serviço público face aos operadores privados. Daremos só três exemplos. Estrela Serrano, comparando as coberturas da eleição presidencial de 2001, na RTP1, na SIC e na TVI, conclui que "existem poucas diferenças nos processos de tratamento da informação. Isso traduz a existência de uma socialização profissional eficaz, uma vez que os três canais adoptam técnicas semelhantes de tratamento da informação [...]. Não seria, todavia, rigoroso concluir que a RTP constitui uma simples cópia dos canais comerciais" (Serrano, 2006: 481). Nuno Goulart Brandão, observando sistematicamente os jornais televisivos das 20 horas, no ano de 2003, nos mesmos

3 - A ERC foi criada pela Lei n. ${ }^{\circ}$ 53/2005, de 8 de novembro; a Lei $n^{0}$ 2/2006, de 14 de fevereiro, criou o Provedor do Ouvinte e o Provedor do Telespectador nos serviços públicos de rádio e de televisão; a Lei n. ${ }^{\circ}$ 8/2007, de 14 de fevereiro, reforçou as competências do Conselho de Opinião. 
canais, conclui que "os telejornais portugueses estão cheios de notícias geradoras de emoção, dramatização e espectacularidade como principais critérios para hierarquização da importância noticiosa” (Brandão, 2006: 222). Felisbela Lopes, tomando como amostra a última semana de novembro de 2006, sustenta que a RTP é a única estação que apresenta uma programação diversificada, contrastando com a oferta monotemática dos dois canais generalistas privados (Lopes, 2007).

Por outro lado, também há registo de ensaios de natureza mais normativa, que procuram retirar da investigação em ciências da comunicação linhas condutoras para uma organização e uma programação mais consentânea com a relevância cultural e a utilidade social do serviço público. Das que conhecemos, a mais interessante foi a contribuição da equipa da Universidade do Minho para o debate público que ocorreu em Portugal em 2002-2003 - uma contribuição inspirada pela ideia força de que "a orientação para a cidadania é o critério determinante da organização" desse serviço (Pinto, 2005: 49).

Haverá, certamente, muitos mais estudos, concluídos ou em curso, que abordem a questão. Não é nossa intenção propor qualquer tipo de síntese, nem teríamos capacidade para fazê-lo. É outro o objetivo: aplicar um conjunto de critérios relativamente simples, vinculados a algumas das missões mais consensualmente atribuídas ao serviço público, usando como material empírico a soma de documentos de prestação de contas, acompanhamento e avaliação disponíveis em Portugal - a saber, os relatórios do cumprimento das obrigações de serviço público, que a RTP tem de apresentar anualmente; os seus planos de atividade e relatórios e contas; as auditorias independentes promovidas pela ERC; o relatório anual de regulação, desta mesma entidade; os relatórios do Provedor do Telespectador; os pareceres do Conselho de Opinião.

\section{Um exercício de avaliação de relevância cultural...}

É inteiramente legítimo proceder à avaliação da qualidade cultural da programação televisiva a partir dos padrões de gosto, aliás plurais, que informem os avaliadores. Os cientistas sociais devem, contudo, evitar fazer dos seus próprios gostos a referência única ou predominante para o exercício da análise empírica. Um distanciamento mínimo face às querelas do gosto constitui, aliás, condição necessária para tomá-las a elas próprias como objeto de estudo e interpretação - e, designadamente, para evitar o preconceito infelizmente muito corrente nas apreciações das elites culturais sobre a televisão generalista, que é pensar que esta não deveria ter em conta os gostos dos públicos a que se dirige, mas sim, apenas, a norma estética e cultural de tais elites. 
Uma maneira expedita de contornar as dificuldades de apreciação qualitativa é, entretanto, referi-la aos critérios que, na doutrina e na legislação europeia e nacional, sustentam a legitimidade e relevância do serviço público de televisão. Assim, para lá das obrigações de garantia de cobertura universal (em termos sociais e territoriais), de prestação de informação isenta, rigorosa e plural, de acolhimento dos tempos de antena e outras formas de expressão cívica e política, de atenção aos símbolos, factos e acontecimentos centrais para a estrutura da comunidade nacional e de orientação específica para os membros dessa comunidade residentes fora do país, assim como para outros interesses chave da política externa nacional, a doutrina e a legislação requerem do serviço público de televisão a satisfação de um conjunto de critérios que podem ser sumariados, para o que agora nos importa, em quatro dimensões fundamentais. Em primeiro lugar, a defesa, afirmação e desenvolvimento da identidade nacional, linguística e cultural, bem como da coesão sociocultural (a televisão como o "laço social", de que fala Wolton, 1999). Em segundo lugar, a promoção da diversidade cultural e da pluralidade das suas expressões - quer no que interliga esta dimensão com a anterior, ou seja, a defesa da singularidade e do valor próprio da cultura nacional, no conspecto de identidades e culturas constitutivas do nosso mundo, quer no que ela significa respeito por, e promoção da diversidade entre géneros culturais, entre correntes estéticas, entre os múltiplos grupos, gostos e expectativas que configuram "o" público da televisão. Em terceiro lugar, a promoção da "criatividade e da excelência cultural" (para usar os termos do Livro Branco sobre o papel da BBC na era digital, que alinha este entre os seis "propósitos públicos" do serviço público britânico, a par de cidadania, educação, representação das nações, regiões e comunidades, afirmação internacional e transição para o digital, cf. Department for Culture, Media and Sport, 2006: 9) - quer dizer, o compromisso do serviço público com a criatividade no sentido amplo, social e cultural, no que ela representa liberdade, experimentação, inovação, desafio, exigência. E, em quarto lugar, o apoio às artes e indústrias culturais nacionais, com natural destaque para a arte e a indústria do cinema e audiovisual.

Nenhuma destas obrigações de natureza mais cultural é exclusiva do serviço público; ao contrário do que muitas vezes se diz, a legislação estende-as a todos os operadores generalistas e investe a entidade reguladora dos poderes indispensáveis à sua verificação. Mas elas adquirem intensidade e modulação próprias no serviço público, que tem especiais responsabilidades em matéria de identidade nacional, diversidade, criatividade e cooperação com o meio artístico e cultural. E é a uma dupla luz que devem ser ponderadas: por um lado, diferenciam-no face aos canais comerciais - e, portanto (juntamente com as restantes missões, de informação e cidadania, já atrás sumariadas), fundamentam a sua existência, atividade e modo de financiamento no 
panorama audiovisual; por outro lado, caraterizam o seu papel e o contributo potencial para o sistema de políticas públicas orientadas para a cultura, a qualificação e a cidadania - e, portanto, legitimam a sua integração em tal sistema.

Podemos, assim, perguntar, com base nos vários documentos de acompanhamento e avaliação, se a programação generalista do serviço público favorece a diversidade, se promove a comunicação de formas culturais nacionais, se se diferencia, nestes termos, face aos concorrentes - e se, no conjunto da atividade, a concessionária participa, e de que modo, no incentivo à criação e produção audiovisual portuguesa. Não devemos, porém, fazer as perguntas numa espécie de vazio abstrato, como se o desempenho de gestores e programadores não fosse condicionado pelas circunstâncias concretas em que ocorre. Entre estas, duas são especialmente relevantes: os recursos financeiros disponíveis; as caraterísticas e tendências das audiências.

O Quadro 2 compara, em diferentes indicadores financeiros, a situação portuguesa de 2009 com a média de 13 países europeus (Alemanha, Áustria, Bélgica, Dinamarca, Espanha, Finlândia, França, Holanda, Irlanda, Itália, Portugal, Reino Unido e Suécia). Todos mostram que a restrição de custos é mais forte entre nós, estabelecendo uma limitação às opções de produção e exibição de conteúdos, que a análise desapaixonada não pode deixar de relevar, e que não se vê como possa ser tão cedo levantada. (Pelo contrário, as decisões tomadas ou anunciadas pelas autoridades governamentais vão no sentido de aumentar a restrição).

\section{Quadro 2: Indicadores de custos e proveitos do serviço público de televisão, em comparação internacional (2009)}

\begin{tabular}{lccc}
\hline & Portugal & Média & Desvio (\%) \\
\hline Custo operacional por habitante (€) & 27,76 & 67,96 & $-59,2$ \\
Fundos públicos por habitante (€) & 22,21 & 52,37 & $-57,6$ \\
Fundos públicos por ponto de audiência (M€) & 5,48 & 21,24 & $-74,2$ \\
Receita de publicidade/Receita total (\%) & 16,00 & $\mathbf{1 6 , 0 0}$ & \\
Fundos públicos por unidade de PIB (\%) & 0,14 & $\mathbf{0 , 1 7}$ & $\mathbf{- 1 7 , 6}$ \\
\hline
\end{tabular}

Fonte: Parecer do Conselho de Opinião anexo ao Relatório do cumprimento das obrigações de serviço público, RTP, 2010, citando os dados da European Broadcasting Union.

Da sua parte, embora entre 2002 e 2010 o par de canais generalistas da RTP tenha, primeiro, recuperado e, depois, estabilizado as audiências em níveis que significam uma efetiva influência social (Quadro 3), o facto é que o leque de programas que motivam maior adesão do público é relativamente reduzido, abrangendo tipicamente telenovelas, jornais televisivos, concursos, talk shows e reality shows, e jogos de futebol (cf. Quadro 4). 
Quadro 3: Share dos canais generalistas e do conjunto de canais de cabo, 20022010

\begin{tabular}{lccccccccc}
\hline & $\mathbf{2 0 0 2}$ & $\mathbf{2 0 0 3}$ & $\mathbf{2 0 0 4}$ & $\mathbf{2 0 0 5}$ & $\mathbf{2 0 0 6}$ & $\mathbf{2 0 0 7}$ & $\mathbf{2 0 0 8}$ & $\mathbf{2 0 0 9}$ & $\mathbf{2 0 1 0}$ \\
\hline RTP1 & 21,1 & 23,8 & 24,7 & 23,6 & 24,5 & 25,2 & 23,8 & 24,0 & 24,2 \\
RTP2 & 5,3 & 5,0 & 4,4 & 5,0 & 5,4 & 5,2 & 5,6 & 5,8 & 5,3 \\
SIC & 31,5 & 30,3 & 29,3 & 27,2 & 26,2 & 25,1 & 24,9 & 23,4 & 23,4 \\
TVI & 31,4 & 28,5 & 28,9 & 30,0 & 30,0 & 29,0 & 30,5 & 28,7 & 27,5 \\
Cabo/outros & 10,6 & 12,3 & 12,7 & 14,1 & 14,0 & 15,4 & 15,2 & 18,2 & 19,7 \\
TOTAL TV & $\mathbf{1 0 0}$ & $\mathbf{1 0 0}$ & $\mathbf{1 0 0}$ & $\mathbf{1 0 0}$ & $\mathbf{1 0 0}$ & $\mathbf{1 0 0}$ & $\mathbf{1 0 0}$ & $\mathbf{1 0 0}$ & $\mathbf{1 0 0}$ \\
\hline
\end{tabular}

Fontes: Marktest, Anuário Media e Publicidade; Obercom, Anuário de Comunicação, 2009/2010.

Quadro 4: Audiências dos canais generalistas, por género de programa, 2008 2010 (em \%)

\begin{tabular}{|c|c|c|c|c|c|c|c|c|c|c|}
\hline & \multicolumn{2}{|c|}{ Total } & \multicolumn{2}{|c|}{ RTP1 } & \multicolumn{2}{|c|}{ RTP2 } & \multicolumn{2}{|c|}{ SIC } & \multicolumn{2}{|c|}{ TVI } \\
\hline & $\begin{array}{c}200 \\
8\end{array}$ & $\begin{array}{c}201 \\
0\end{array}$ & $\begin{array}{c}200 \\
8\end{array}$ & $\begin{array}{c}201 \\
0\end{array}$ & $\begin{array}{c}200 \\
8\end{array}$ & $\begin{array}{c}201 \\
0\end{array}$ & $\begin{array}{c}200 \\
8\end{array}$ & $\begin{array}{c}201 \\
0\end{array}$ & $\begin{array}{c}200 \\
8\end{array}$ & $\begin{array}{c}201 \\
0\end{array}$ \\
\hline Arte e cultura & 0,0 & 0,0 & 0,1 & 0,0 & 0,1 & 0,1 & 0,0 & 0,0 & 0,0 & 0,0 \\
\hline $\begin{array}{l}\text { Cultura } \\
\text { geral/Conhecime } \\
\text { nto }\end{array}$ & 3,5 & 3,2 & 2,5 & 2,7 & 23,4 & 20,9 & 2,5 & 1,9 & 1,2 & 1,3 \\
\hline Desporto & 5,3 & 4,6 & 6,5 & 7,2 & 12,2 & 9,2 & 2,4 & 3,2 & 5,5 & 2,5 \\
\hline Divertimentot & 18,2 & 20,0 & 31,4 & 31,3 & 2,1 & 5,0 & 17,5 & 16,3 & 11,6 & 16,0 \\
\hline Ficção & 31,4 & 29,7 & 13,6 & 11,9 & 15,9 & 16,8 & 35,1 & 36,0 & 45,1 & 42,5 \\
\hline Informação & 22,6 & 23,8 & 33,3 & 35,0 & 11,2 & 11,4 & 21,8 & 22,6 & 16,9 & 17,5 \\
\hline Juventude & 2,7 & 2,7 & 0,1 & 0,1 & 31,1 & 34,6 & 1,9 & 1,3 & 0,2 & 0,2 \\
\hline Outro & 3,2 & 2,6 & 2,9 & 2,4 & 2,7 & 0,9 & 3,5 & 2,8 & 3,2 & 3,1 \\
\hline Publicidade & 13,1 & 13,3 & 9,5 & 9,4 & 1,3 & 1,2 & 15,3 & 15,9 & 16,2 & 17,0 \\
\hline Total & 100 & 100 & 100 & 100 & 100 & 100 & 100 & 100 & 100 & 100 \\
\hline
\end{tabular}

Fonte: dados da Marktest, usados por Obercom, Anuário de Comunicação 2009/2010.

Vejamos, então - não no vazio, mas sim no quadro destas duas importantes condições, as disponibilidades financeiras e a estrutura e orientação das audiências - como é que, no último ano para que há informação disponível, 2010 (ou o ano mais próximo), a programação do serviço público generalista correspondeu aos critérios atrás assinalados: diversidade, diferenciação, cooperação com a criação artística e a indústria audiovisual.

Os gráficos 1 a 4 mostram sucessivamente que: a) os dois canais públicos apresentam a maior diversidade de géneros emitidos; b) a RTP 2 se destaca no peso concedido aos programas classificáveis no macrogénero "cultura geral e conhecimento"; c) em comparação com outros países europeus, o serviço público português apresenta um fraco desempenho, em matéria de programação cultural, no seu primeiro canal generalista, mas é o mais bem cotado, no segundo canal. 


\section{Gráfico 1: Número de géneros emitidos em 2010 pelos canais generalistas}

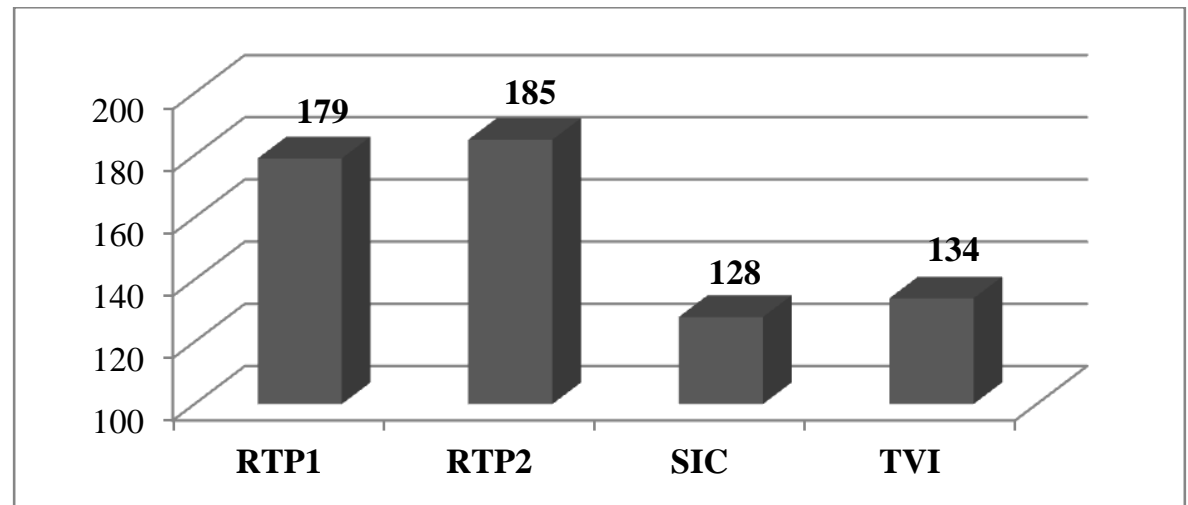

Dados citados no Relatório do cumprimento das obrigações de serviço público, RTP, 2010

Gráfico 2: Programação em 2010 dos canais generalistas, por seis macrogéneros (horas de emissão)

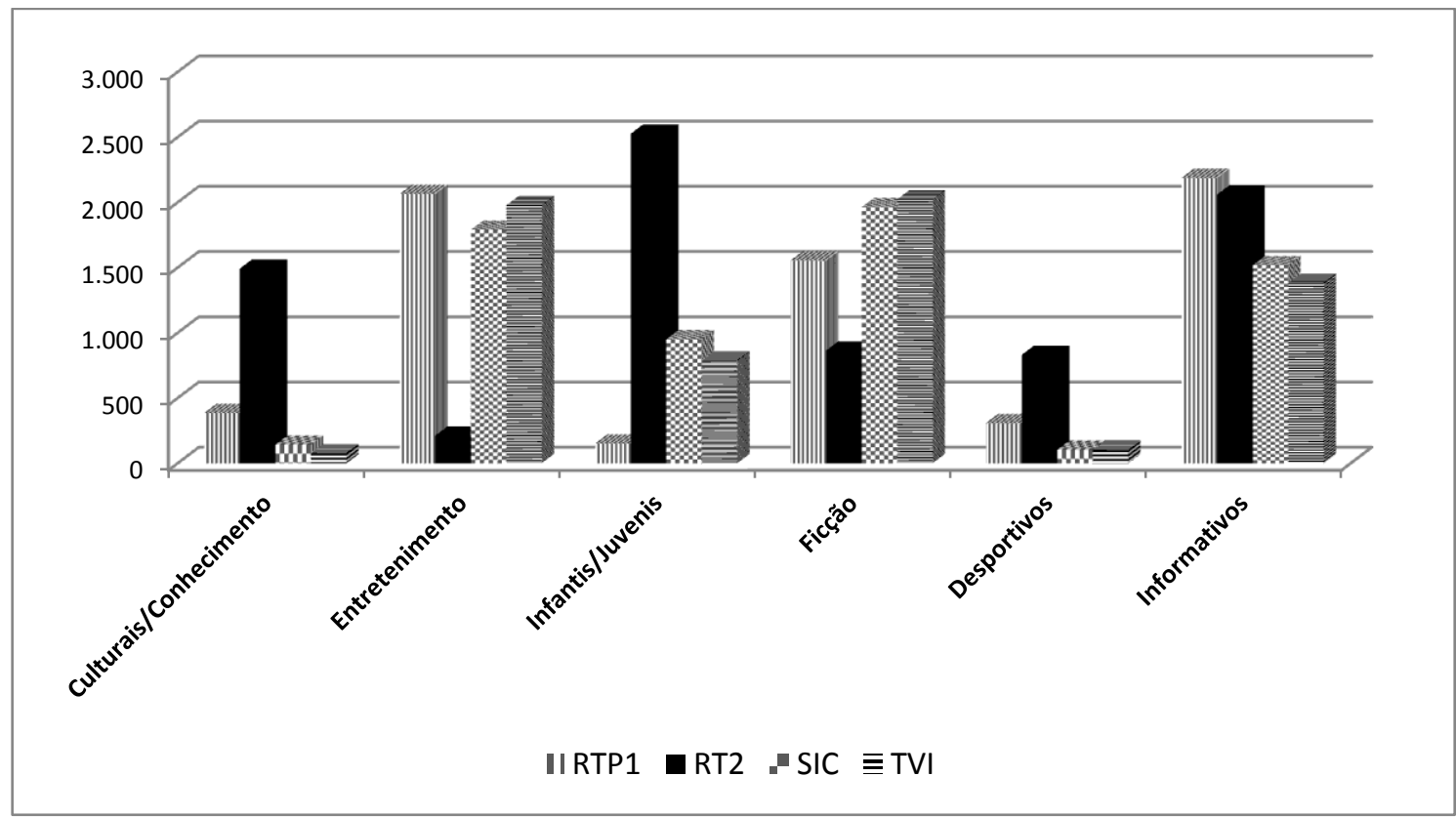

Dados citados no Relatório do cumprimento das obrigações de serviço público, RTP, 2010 
Gráfico 3: A programação cultural do primeiro canal do serviço público em 2oo8, em comparação europeia (em horas de emissão)

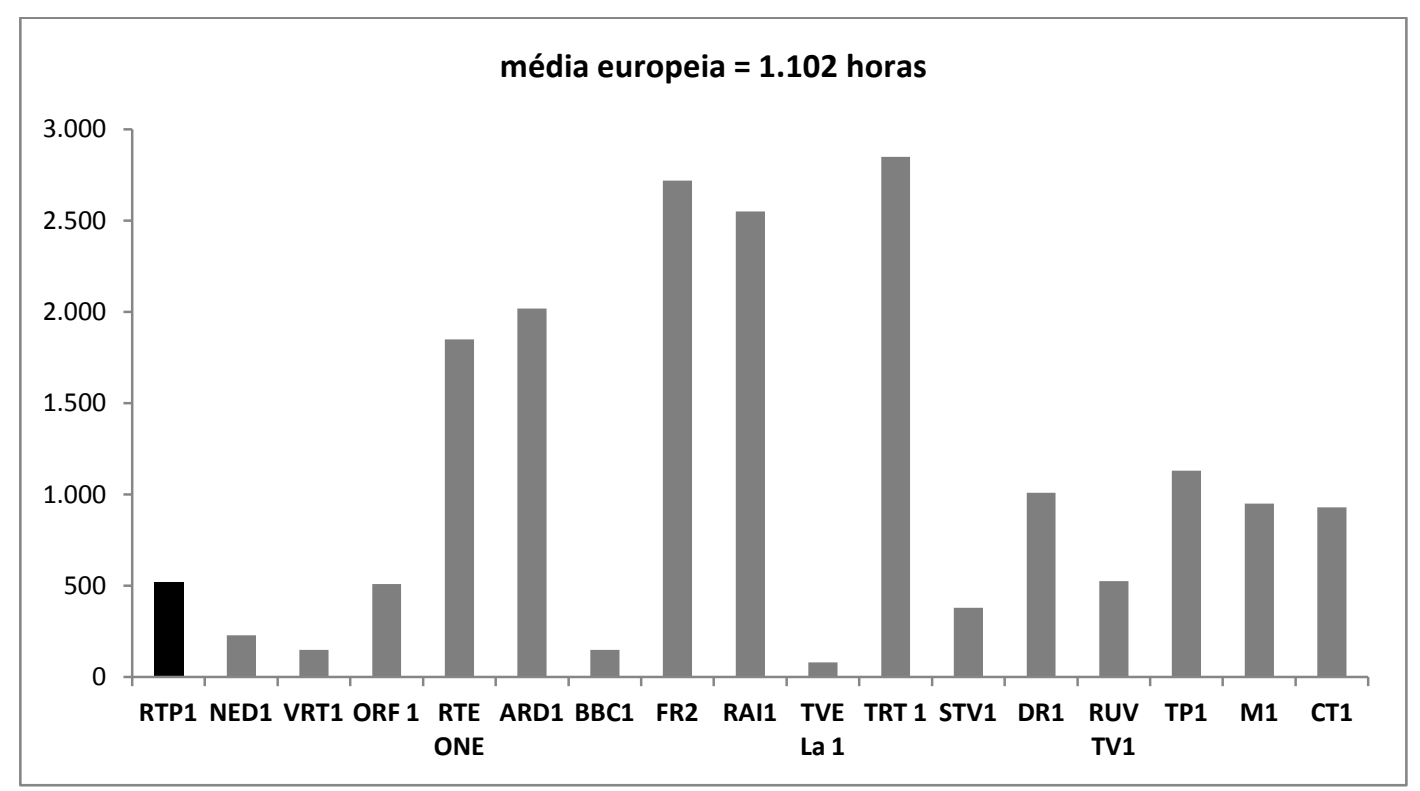

Fonte: Relatório do cumprimento das obrigações de serviço público, RTP, 2010 , citando EBU GUIDES EBU Member's TV Programming - Total Broadcast Output Hours - 2008 (July 2009)

Gráfico 4: A programação cultural do segundo do serviço público, em comparação europeia (em horas de emissão)

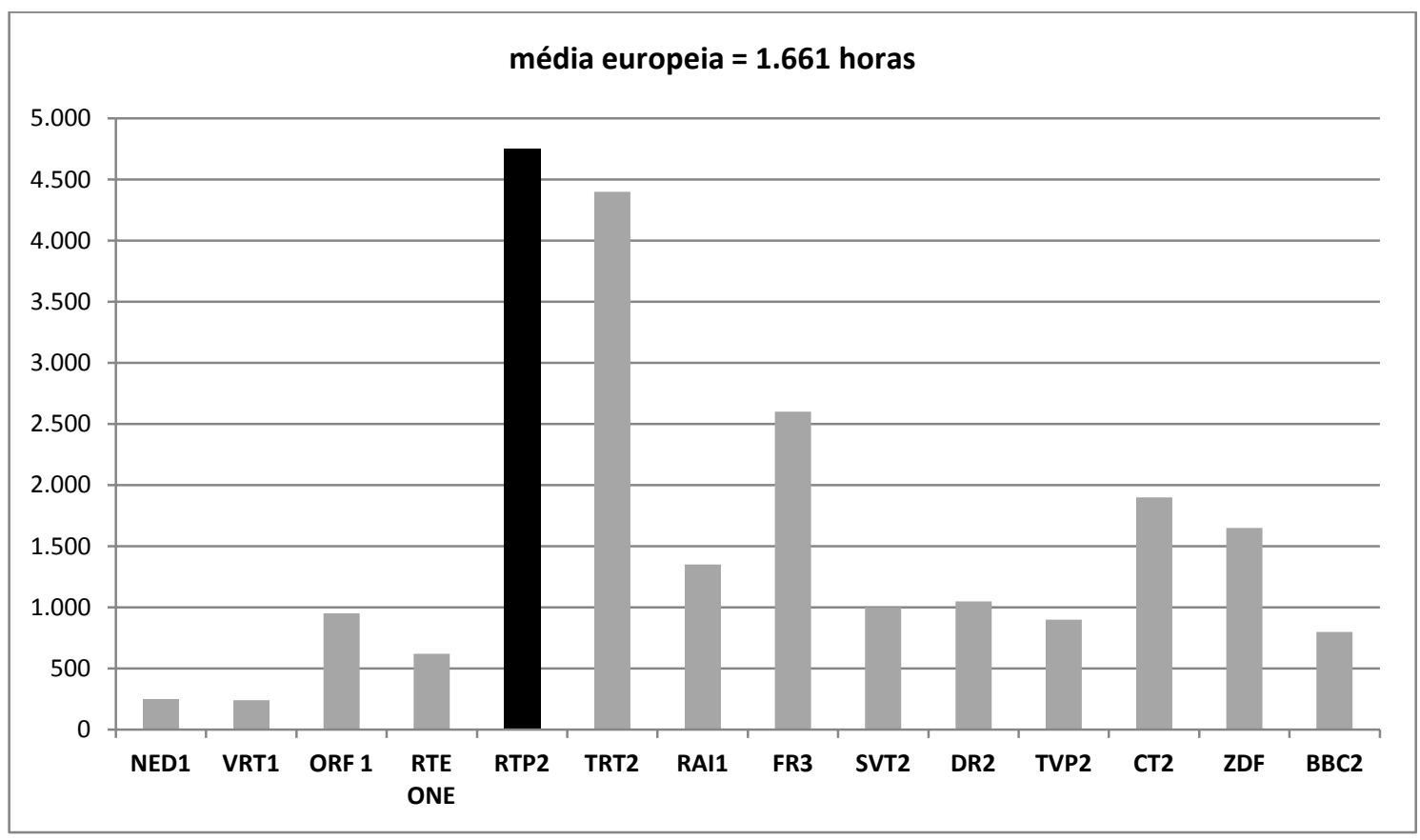

Fonte: Relatório do cumprimento das obrigações de serviço público, RTP, 2010 , citando EBU GUIDES -EBU Member's TV Programming - Total Broadcast Output Hours - 2008 (July 2009)

Já quanto à participação da concessionária do serviço público na produção artística e na indústria do cinema e audiovisual, são dois os dados mais relevantes. O primeiro é que, num quadro dominado pela especialização relativa dos dois operadores privados - 
vivendo criticamente a programação da SIC da exibição de telenovelas brasileiras e a programação da TVI da exibição de telenovelas portuguesas que ela própria produz (tendo como consequência ser a TVI um ator chave da indústria audiovisual portuguesa) - a diferenciação da RTP tem sido a aposta em seriados portugueses de outra filiação programática, mas com um nível de investimento relativamente pobre. $\mathrm{O}$ segundo dado é que, por força das determinações da lei e do contrato, a RTP é o único operador que junta à participação no Fundo de Investimento do Cinema e Audiovisual (FICA, cuja lógica era a reunião de recursos reversíveis para os próprios investidores, visando a criação de escala no mercado audiovisual) a parceria com o Instituto do Cinema e Audiovisual (ICA) no apoio à realização e produção de filmes segundo critérios de valor artístico e cultural. Aliás, coerentemente, enquanto o FICA esteve ativo, a RTP contribuiu menos do que os operadores privados, reservando a maior fatia do esforço financeiro aos apoios à produção dos filmes selecionados nos concursos do ICA (em relação aos quais tem, depois, um direito-dever de exibição).

\section{5. ...E do seu impacto financeiro}

Desde 2003, os fundos públicos de que beneficia a RTP (provenham eles do Orçamento do Estado, como indemnização compensatória ou dotação de capital, ou da contribuição para o audiovisual), são expressamente alocados a diferentes rubricas de organização e conteúdos. (As receitas de publicidade são afetas ao serviço de dívida). Por exemplo, em 2010, dos 285 milhões de euros de fundos públicos, 43 milhões foram destinados à rádio, 143 milhões à RTP1, 42 milhões à RTP2, 16 milhões aos canais internacionais, 17 milhões aos canais regionais, 2 milhões à parceria com o ICA, etc.

Ora, como dispomos, para a televisão, da distribuição de programas pelos chamados macrogéneros, durante o ano de 2008, podemos fazer um exercício de cálculo do custo daqueles macrogéneros que julguemos mais próximos de uma programação cultural, para termos uma ordem de grandeza do que significa o investimento em cultura nos dois canais generalistas da televisão pública portuguesa. O Quadro 5 apresenta o exercício, permitindo formar uma ideia de quanto significou, financeiramente, a programação com conteúdos documentais e de divulgação cultural, de ficção (a que agregámos, por nos parecer lógico, o custo do protocolo com o ICA) e conteúdos musicais e eruditos. Chegamos assim a cerca de 48 milhões de euros/ano, uns 20\% do total de fundos públicos nesse ano disponíveis para a empresa. 


\section{Quadro 5: A afetação do financiamento público a macrogéneros de natureza cultural, em 2008, RTP1 e RTP2}

\begin{tabular}{|c|c|c|}
\hline \multirow[b]{2}{*}{ unidade: $1.000 €$} & \multirow{3}{*}{$\frac{\text { RTP1 }}{131.083,6}$} & \multirow{3}{*}{$\begin{array}{l}\text { RTP2 } \\
41.921,7\end{array}$} \\
\hline & & \\
\hline $\begin{array}{l}\text { Financiamento público } \quad \text { a } \\
\text { afetar }\end{array}$ & & \\
\hline Indemnização compensatória & $71.076,8$ & \\
\hline Contribuição para o Audiovisual & $10.884,7$ & $41.921,7$ \\
\hline Dotação de capital & $49.122,1$ & \\
\hline \multicolumn{3}{|l|}{$\begin{array}{l}\text { Distribuição } \\
\text { Macrogénreos }\end{array}$} \\
\hline Culturais/Conhecimento & $6 \%$ & $17 \%$ \\
\hline Ficção & $22 \%$ & $10 \%$ \\
\hline Infantis/Juvenis & $2 \%$ & $27 \%$ \\
\hline Desportivos & $5 \%$ & $12 \%$ \\
\hline Informação & $30 \%$ & $27 \%$ \\
\hline Divertimento & $32 \%$ & $1 \%$ \\
\hline Institucionais e religiosos & $2 \%$ & $6 \%$ \\
\hline \multicolumn{3}{|l|}{ Afetação por Macrogéneros } \\
\hline Culturais/Conhecimento & $7.602,9$ & $7.168,6$ \\
\hline Ficção & $28.838,4$ & $4.066,4$ \\
\hline Infantis/Juvenis & $2.359,5$ & $11.276,9$ \\
\hline Desportivos & $6.947,4$ & $5.114,4$ \\
\hline Informação & $39.849,4$ & $11.151,2$ \\
\hline Divertimento & $42.340,0$ & 503,1 \\
\hline Institucionais e religiosos & $3.146,0$ & $2.683,0$ \\
\hline Total & $131.083,6$ & $41.963,6$ \\
\hline \multirow[t]{2}{*}{ Total dos itens selecionados } & $36.441,2$ & $11.235,0$ \\
\hline & \multicolumn{2}{|c|}{$47.676,3$} \\
\hline $\begin{array}{r}\text { Peso no financiamento global } \\
\text { TV }\end{array}$ & \multicolumn{2}{|c|}{$20,3 \%$} \\
\hline
\end{tabular}

Cálculos dos autores, cruzando informação contida no Relatório de auditoria à empresa concessionária do serviço público de televisão, Rádio e Televisão de Portugal, S.A. (ERC, 2008) - para a afetação do financiamento público - e - no que toca à distribuição de programas emitidos segundo os macrogéneros no Relatório de regulação de 2008, da ERC.

Veja-se agora a previsão da distribuição do teto de despesa para a cultura aprovado no Orçamento do Estado para 2012, tal como o secretário de Estado da Cultura a apresentou, na Assembleia da República, em novembro de 2011, no quadro da discussão da respetiva proposta de Lei (Quadro 6): 


\section{Quadro 6: Distribuição do Orçamento do Estado para a cultura, por grandes} domínios de intervenção, em 2012 (em milhões de euros)

\begin{tabular}{|c|c|c|}
\hline Domínios de intervenção & 2012 & $\%$ \\
\hline $\begin{array}{lll}\begin{array}{l}\text { Apoio a } \\
\text { Culturais }\end{array} & \text { Atividades } & \text { Socio } \\
\end{array}$ & 13,17 & $8 \%$ \\
\hline Apoio às Artes & 44,32 & $27 \%$ \\
\hline Arquivos e Bibliotecas & 21,18 & $13 \%$ \\
\hline Cinema & 15,47 & $9 \%$ \\
\hline Património & 60,96 & $36 \%$ \\
\hline $\begin{array}{l}\text { Serviços de Governação e de } \\
\text { Suporte }\end{array}$ & 12,01 & $7 \%$ \\
\hline Total & 167,1 & $100 \%$ \\
\hline
\end{tabular}

Fonte: Secretaria de Estado da Cultura, apresentação do Orçamento do Estado para 2012 ao Parlamento, novembro 2011, disponível no sítio eletrónico da Assembleia da República - Comissão de Orçamento, Finanças e Administração Pública.

Os 48 milhões de euros gastos, em 2008, pela RTP em programação de natureza mais cultural comparariam, pois, com os 44 milhões do total de apoio às artes previsto para 2012. Se acrescentássemos àquele número o valor despendido, nas Antenas 1, 2 e 3 da rádio pública, com o macrogénero "divulgação musical, alinhamento musical e concertos" (Quadro 7), chegaríamos a um valor na ordem dos 66 milhões de euros - o qual superaria a soma dos apoios previstos em 2012 para as artes e o cinema, ou o valor reservado para todo o património... 


\section{Quadro 7: A afetação do financiamento público a macrogéneros de natureza} cultural, em 2008, na Antena1, Antena 2 e Antena 3

\begin{tabular}{|c|c|c|c|}
\hline unidade: $1.000 €$ & ANTENA 1 & ANTENA 2 & ANTENA 3 \\
\hline $\begin{array}{l}\text { Financiamento público a } \\
\text { afetar }\end{array}$ & 18.083,0 & $6.126,0$ & $5.834,5$ \\
\hline \multicolumn{4}{|l|}{$\begin{array}{l}\text { Distribuição dos } \\
\text { Macrogénreos }\end{array}$} \\
\hline Informativo & $24,6 \%$ & $1,1 \%$ & $2,0 \%$ \\
\hline Desportivo & $11,2 \%$ & $0,0 \%$ & $0,0 \%$ \\
\hline $\begin{array}{l}\text { Divulgação musical, } \\
\text { alinhamento musical e } \\
\text { concertos }\end{array}$ & $47,3 \%$ & $91,6 \%$ & $80,0 \%$ \\
\hline Programa de palavra & $14,4 \%$ & $5,6 \%$ & $12,0 \%$ \\
\hline Institucionais/Religioso & $1,2 \%$ & $0,2 \%$ & $0,2 \%$ \\
\hline Continuidade & $1,3 \%$ & $1,5 \%$ & $6 \%$ \\
\hline \multicolumn{4}{|l|}{ Afetação por Macrogéneros } \\
\hline Informativo & $4.446,6$ & 66,8 & 121,4 \\
\hline Desportivo & $2.027,1$ & 0,0 & 0,0 \\
\hline $\begin{array}{l}\text { Divulgação musical, } \\
\text { alinhamento musical e } \\
\text { concertos }\end{array}$ & $8.553,3$ & $5.611,4$ & $4.653,6$ \\
\hline Programa de palavra & $2.604,0$ & 343,1 & 690,8 \\
\hline Institucionais/Religioso & 217,0 & 12,3 & 11,7 \\
\hline Continuidade & 235,1 & 91,9 & 357,1 \\
\hline Total & 18.083,1 & $6.125,5$ & $5.834,6$ \\
\hline \multirow[t]{2}{*}{ Total dos itens selecionados } & $8.553,3$ & $5.611,4$ & $4.653,6$ \\
\hline & \multicolumn{3}{|c|}{ 18.818,3 } \\
\hline $\begin{array}{l}\text { Peso no financiamento } \\
\text { global Radio }\end{array}$ & \multicolumn{3}{|c|}{$42,0 \%$} \\
\hline
\end{tabular}

Cálculos nos termos indicados no Quadro 5

Este exercício é muito grosseiro, evidentemente. Tentamos sugerir aos leitores uma ordem de grandeza. Com um só e simples objetivo: recordar a relevância, também em termos financeiros, dessa função no serviço público de comunicação social, que poderá ser entendida, assim o queiramos, como um dos recursos da política cultural - e, portanto, a escala completamente diferente em que ela colocaria esta política, se acaso fosse como tal concebida e efetivada.

\section{Súmula e pistas de desenvolvimento}

2002 marcou o início de um novo ciclo para o serviço público português de rádio e televisão. Neste ciclo, melhorou significativamente o financiamento, quer do ponto de vista do volume quer quanto à regularidade do processamento, terminando com a espiral de endividamento a que a empresa concessionária havia sido submetida e criando condições para o seu saneamento; ao mesmo tempo que diminuíram, também significativamente, os custos operacionais, através de medidas de fusão e racionalização organizacional e de modernização tecnológica. A RTP ganhou uma estabilidade e 
profissionalização na sua administração como nunca tinha conseguido - bem simbolizadas no facto de, em 2005 e pela primeira vez na sua história, a uma mudança de orientação política do governo não ter correspondido uma mudança na administração e pelo não menos relevante facto de o mesmo se ter verificado em 2011. Ao contrário do que prenunciava o debate político de 2002, o serviço público acabou por não perder nenhum dos seus serviços, antes os desenvolveu. As obrigações foram reforçadas e densificadas, estabelecendo-se desde 2008 um quadro de metas quantitativas a cumprir. Foram aprofundados os mecanismos de independência profissional dos gestores e programadores (respetivamente face ao governo e face ao governo e à administração) e, do outro lado, os mecanismos de prestação de contas, regulação e acompanhamento social e político-parlamentar da atividade e dos resultados (mecanismos tais como a fiscalização pela Entidade Reguladora da Comunicação Social, as auditorias independentes, os Provedores, o Conselho de Opinião ou as audições parlamentares dos responsáveis).

Esta evolução não conduziu a Rádio e Televisão de Portugal a nenhum estado de abundância, nem tal era o seu propósito. Como o quadro 2 atrás mostrou, os custos e os proveitos do serviço público português estão carateristicamente abaixo dos comparadores europeus. Pelo contrário, foi-lhe imposta uma redução de custos. Mesmo assim, e não obstante o arrefecimento da disputa partidária, foi constante ao longo da década que aqui consideramos o questionamento no espaço público (e, em particular, na chamada imprensa popular) do custo e da relação entre custo e qualidade na televisão pública. Esta conseguiu recuperar e estabilizar audiências, demonstrar maior eficiência económica, afirmar alguma diferenciação face ao panorama da televisão generalista (muito dominado pela programação de pendor monotemático) e, sobretudo, ver reconhecida a relevância e credibilidade, nesse mesmo panorama, da informação produzida (fosse em termos noticiosos, fosse em termos de opinião e debate). Enfrentou, porém, e enfrenta problemas que não lhe são exclusivos, antes desafiam todo o modelo europeu, mas que nela adquirem particular acuidade.

Alguns dos problemas decorrem ainda das condições da abertura do meio à iniciativa privada, outros têm mais diretamente a ver com o contexto da era digital. A dupla crise, de influência e de legitimidade social, do serviço público - bem identificada por Arons de Carvalho (2009: 152-171), em termos que damos por reproduzidos - está longe de vencida. Num quadro de diversificação dos modos e tempos de acesso e de consumo televisivo; de multiplicação das plataformas de distribuição e receção de conteúdos; de maior presença e impacto de serviços de programas temáticos e de outros tipos de serviços audiovisuais, com a consequente erosão da televisão generalista e de acesso 
livre e com a correlativa emergência de uma questão que a televisão nunca havia anteriormente enfrentado - a dualidade social no acesso aos conteúdos, porque alguns, e entre eles os mais apelativos ou qualificados, são pagos; num quadro de custos crescentes e receitas comerciais em queda, de concorrência mais aguda e em padrões de mais baixo valor - neste quadro, são óbvios os desafios que enfrenta o serviço público, os limites para a sua sustentação financeira no esforço pedido aos contribuintes, as exigências, muitas vezes desproporcionadas, que lhe são colocadas pelas audiências, pela opinião publicada, pelos grupos de interesse e pelos poderes políticos e sociais, e são também óbvias as suas especiais responsabilidades pela manutenção de níveis aceitáveis de coesão e integração social, de independência e rigor informativo, de acolhimento das diferentes expressões, de ética de antena e de qualidade de conteúdos. Numa era que é ao mesmo tempo concorrencial e digital, não são fáceis, embora sejam vários e prometedores, os caminhos de realização daquelas que, ditas desta ou daquela maneira, continuam a ser as finalidades centrais do serviço público de televisão: informar e formar, promover a cidadania e favorecer a identidade coletiva, seja no plano patrimonial, seja no plano criativo, garantir a diversidade na oferta de lazer, ocupação, símbolos, informações, conhecimentos, bens culturais e oportunidades de comunicação, expressão e participação pública.

Agora que tudo indica que se vai iniciar um novo ciclo na evolução do serviço público português, com essa rutura essencial com a situação presente e com o modelo europeu que é a prometida redução da televisão pública generalista a um só canal, e sem publicidade comercial, talvez valha a pena ter em conta a análise do período que se estendeu, sem descontinuidades de maior, entre 2002 e $2012^{4}$.

Limitámo-nos, aqui, a propô-lo, sugerindo um ângulo de análise que nos parece demasiado esquecido: a relevância do serviço público de comunicação social como recurso cultural - designadamente no âmbito das políticas públicas para a cultura. Há matéria de sobra para a investigação empírica conduzida pelos critérios das ciências da comunicação, da sociologia ou da economia. Uma investigação que não se deixe sobrelevar pelas meras apreciações de gosto ou pelo jogo cruzado dos interesses e das visões de mundo (tão notoriamente influentes quando se trata de atribuir missões ou indicar públicos alvo para a rádio ou a televisão pública); e que procure fazer uma leitura objetiva e distanciada dos quadros normativos e das concretas condições de

4 - Como já atrás se disse, em virtude de divergências insanáveis entre os partidos da coligação, o Governo acabaria por adiar, em janeiro de 2013, a processo de privatização da RTP. Não obstante, a indefinição que a empresa e o serviço público viveram no segundo semestre de 2011 e em todo o ano de 2012 acabou por fazer voltá-los a tempos de instabilidade, incerteza e erosão que, na prática, significaram uma efetiva rutura com o ciclo que havia sido iniciado em 2002. (Nota acrescentada em janeiro de 2013). 
cumprimento, das estratégias de ação e dos respetivos indicadores de desempenho e resultado, e não por referência a modelos ideais mas sim contextualizando-os nas realidades económicas, sociais e políticas.

Do exercício analítico que fizemos parece-nos ressaltarem quatro conclusões fundamentais. A primeira é que, ao longo do ciclo de 2002 a 2012, foi clarificado e densificado o quadro de obrigações e metas legais e contratuais e os correlativos instrumentos de acompanhamento, controlo e verificação, no que importa ao serviço público. A segunda é que este recuperou e consolidou uma margem (cuja amplitude careceria de ser discutida, mas de qualquer modo uma margem) de diferenciação, no panorama audiovisual. A terceira conclusão é que o peso específico relativo da programação e atividade conexa ligada às dimensões da cultura, do conhecimento e da formação, constitui (juntamente com os seus equivalentes do lado da informação, e a par das restantes e conhecidas especificidades do serviço público, como a cobertura universal, a afirmação internacional ou os direitos de antena), constitui, dizíamos, um fator de diferenciação e um conteúdo daquela margem. E a quarta conclusão é que, maior ou menor, mais robusta ou mais frágil, consolidada ou precária, em crescimento ou em regressão, a margem de diferenciação própria do serviço público representa, em termos de custo de serviço, público atingido e nível de influência conseguida, um não despiciendo ativo, que compara bem, nesses planos, com qualquer dos grandes instrumentos disponíveis da política cultural - e assim poderá ou poderia constituir um recurso crítico dessa política.

Evidentemente, pensar o serviço público de comunicação social como um recurso de política cultural abre caminhos, talvez ainda por experimentar com vontade e energia, para a própria política pública para esse serviço. Esse seria já, porém, outro tema..

\section{Referências bibliográficas}

Brandão, Nuno Goulart (2006): Prime time: do que falam as notícias dos telejornais, Cruz Quebrada: Casa das Letras.

Cardoso, Gustavo (2006): Os media na sociedade em rede, Lisboa: Gulbenkian.

Cardoso, Gustavo; Espanha, Rita; Araújo, Vera, orgs. (2009): Da comunicação de massa à comunicação em rede, Porto: Porto Editora.

Carvalho, Alberto Arons de (2009): A RTP e o serviço público de televisão, Coimbra: Almedina. 
Department for Culture, Media and Sport (2006): A public service for all: the BBC in the digital age. White paper presented to Parliament by the Secretary of State for Culture, Media and Sport, Londres.

Lopes, Felisbela (2007): "Dos excessos da TV generalista: retratos da informação semanal emitida em horário nobre”, Comunicação e sociedade, 11: 135-148.

Pinto, Manuel (2002): Televisão, família e escola: pistas para agir, Lisboa: Presença.

Pinto, Manuel, coord. (2005, [2003]): Televisão e cidadania: contributos para o debate sobre o serviço público, 2. ${ }^{\mathrm{a}}$ ed. rev., Porto: Camo das Letras.

Neves, José Soares (2011): Práticas de leitura da população portuguesa no início do século XXI, tese de doutoramento, Lisboa: ICSTE-IUL.

Rebelo, José, coord. (2008): Estudo da recepção dos meios de comunicação social, Lisboa: Entidade Reguladora da Comunicação Social.

Serrano, Estrela (2006): Jornalismo político em Portugal: a cobertura de eleições presidenciais na imprensa e na televisão (1976-2001), Lisboa: Colibri/Instituto Politécnico de Lisboa.

Wolton, Dominique (1999 [1997]): Pensar a comunicação, trad., Lisboa: Difel.

Augusto Santos Silva é doutorado em Sociologia, professor da Faculdade de Economia da Universidade do Porto, e investigador do Instituto de Sociologia da Faculdade de Letras da Universidade do Porto.

asilva@fep.up.pt

Maria José Ribeiro é licenciada em Economia. Trabalha atualmente na Câmara Municipal de Lisboa.

patagonia@vizzavi.pt 